\title{
Phylogenetic analysis of 165 mitochondrial DNA data in sloths and anteaters
}

\author{
Maria Claudene Barros ${ }^{1}$, Iracilda Sampaio ${ }^{2}$ and Horacio Schneider ${ }^{2}$ \\ ${ }^{1}$ Universidade Estadual do Maranhão, CESC, Caxias, MA, Brazil. \\ ${ }^{2}$ Universidade Federal do Pará, Núcleo de Estudos Costeiros, Campus de Bragança, \\ Bragança, Pará, Brazil.
}

\begin{abstract}
We sequenced part of the 16S rRNA mitochondrial gene in 17 extant taxa of Pilosa (sloths and anteaters) and used these sequences along with GenBank sequences of both extant and extinct sloths to perform phylogenetic analysis based on parsimony, maximum-likelihood and Bayesian methods. By increasing the taxa density for anteaters and sloths we were able to clarify some points of the Pilosa phylogenetic tree. Our mitochondrial 16S results show Bradypodidae as a monophyletic and robustly supported clade in all the analysis. However, the Pleistocene fossil Mylodon darwinii does not group significantly to either Bradypodidae or Megalonychidae which indicates that trichotomy best represents the relationship between the families Mylodontidae, Bradypodidae and Megalonychidae. Divergence times also allowed us to discuss the taxonomic status of Cyclopes and the three species of three-toed sloths, Bradypus tridactylus, Bradypus variegatus and Bradypus torquatus. In the Bradypodidae the split between Bradypus torquatus and the proto-Bradypus tridactylus / B. variegatus was estimated as about 7.7 million years ago (MYA), while in the Myrmecophagidae the first offshoot was Cyclopes at about 31.8 MYA followed by the split between Myrmecophaga and Tamandua at 12.9 MYA. We estimate the split between sloths and anteaters to have occurred at about 37 MYA.
\end{abstract}

Key words: pilosa, sloths, anteaters, phylogeny, mitochondrial DNA, rDNA16S.

Received: September 25, 2002; accepted: December 20, 2002.

\section{Introduction}

The monophyletic nature of the Xenarthran (Edentata, Mammalia) group (armadillos, sloths and South American anteaters) is well supported by both morphological and molecular data, members of this group possessing an exclusive morphological synapomorphism in the form of additional atypical articulations between vertebrae (Engelmann, 1985; Patterson et al., 1992; Rose and Emry, 1993; Gaudin, 1999) and a clear molecular synapomorphism (unique among the Eutheria) in the absence of three consecutive amino acids in the alpha crystalline protein of the eye lens (De Jong et al., 1998; van Dijk et al., 1999), while nuclear and mitochondrial gene sequences also support monophyly (Delsuc et al., 2001). Within the xenarthrans, morphological analysis suggests a closer affinity between sloths and anteaters (grouped together as the Pilosa clade) relative to armadillos (the Cingulata) (McKenna and Bell, 1997) and molecular data also convincingly supports the monophyly of sloths and anteaters (Delsuc et al., 2001; Murphy et al. 2001).

Send correspondence to Horacio Schneider. Alameda Leandro Ribeiro sn. 68600-000,Bragança, Pará, Brazil. E-mail: hschneider@uol.com.br.
Sloths, according to McKenna and Bell (1997), are the most diverse Xenarthran group with about 100 known fossil genera, the majority of which were very common in the Americas in the Pleistocene but became extinct around 10,000 years ago such that only five species belonging to two genera, Choloepus (two-toed sloths) and Bradypus (three-toed sloths), survive today in Central and South America. McKenna and Bell (1997) arranged sloths into two infraorders, the extinct Mylodonta (Myodontidae) and the Megatheria, consisting of the extinct Megatheriidae, the Megalonychidae containing the genera Choloepus and the Bradypodidae containing the genus Bradypus. The phylogenetic relationships between extinct and extant taxa are still controversial and the molecular data currently available for the Pilosa group are scarce and poorly represented in terms of the diversity of the taxa examined.

Molecular phylogenetic analysis using $12 \mathrm{~S}$ and $16 \mathrm{~S}$ mitochondrial genes suggested that the fossil Mylodon darwinii (Mylodontidae) was more closely related to the two-toed Megalonychidae than to the three-toed Bradypodidae sloths (Höss et al., 1996). Greenwood et al. (2001) compared the cytochrome B (CytB) and $12 \mathrm{~S}$ sequences of two extinct sloths Mylodon darwinii (Mylodontidae) and Nothrotheriops shastensis (Megatheriidae), with living 
relatives from the two-toed Megalonychidae and the threetoed Bradypodidae, the combined dataset tending to support grouping the megalonychid sloths with the mylodontids and the bradypodids with the megatheriids.

Another important question in Xenarthran phylogeny is the relationships of the three anteater genera Tamandua, Myrmecophaga and Cyclopes within the family Myrmecophagidae. There is a consensus that Cyclopes is the most ancient lineage and that Tamandua and Myrmecophaga share the most recent common ancestor in anteater evolution (Delsuc et al., 2001). Even though there are large molecular differences between Cyclopes and the other two anteaters discussion on the taxonomic ranking inside the Myrmecophagidae clade has been completely ignored, this being one question which will be addressed in this paper.

In the work described in this paper we sequenced part of the 16Sr RNA mitochondrial gene from 17 extant taxa of Pilosa (sloths and anteaters) and used these sequences along with GenBank sequences of both extant and extinct sloths to perform phylogenetic analysis based on parsimony, maximum-likelihood and Bayesian methods. By increasing the taxa density for anteaters and sloths we were able to clarify some points of the Pilosa phylogenetic tree. Divergence times also allowed us to discuss the taxonomic status of Cyclopes and the three species of three-toed sloths, Bradypus tridactylus, Bradypus variegatus and Bradypus torquatus.

\section{Materials and Methods}

Total DNA was obtained from blood or from a small piece of ear skin from the sloths Bradypus tridactylus, Bradypus variegatus, Bradypus torquatus and Choloepus didactylus and the anteaters Cyclopes didactylus, Tamandua tetradactyla and Myrmecophaga tridactyla (Table 1). The animals came from various Brazilian states and regions: Serra da Capivara National Park in the state of
Piauí, Bragança in the northeast state of Pará, and the states of Bahia and Paraíba. The animals used were healthy adults of both sexes and were not harmed by the procedures. Blood or tissues were transported to our laboratory and processed immediately or stored until needed. For DNA extraction blood or tissues were digested with ribonuclease for $1 \mathrm{~h}$ at $37^{\circ} \mathrm{C}$ followed by Proteinase $\mathrm{K}$ for $2-4 \mathrm{~h}$ (or overnight) at $55{ }^{\circ} \mathrm{C}$ and the DNA purified by standard phenol/chloroform extraction and precipitation with isopropanol (Sambrook et al., 1989).

For each DNA sample a fragment of about 500 base pairs of the mitochondrial rRNA $16 \mathrm{~S}$ gene was amplified using the 5'-CGCCTGTTTATCAAAAACAT-3' (L2510) and 5'-TTTCCCCGCGGTCGCCCC-3' (H3059) primers described by Palumbi et al. (1991). PCR amplification was performed in $100 \mu \mathrm{L}$ of reaction mixture containing $16 \mu \mathrm{L}$ of $1.25 \mathrm{mM}$ dNTP, $10 \mu \mathrm{L}$ of buffer (10X conc.), $4 \mu \mathrm{L}$ of $25 \mathrm{mM} \mathrm{MgCl}_{2}, 1 \mu \mathrm{L}$ of each primer $(200 \mathrm{ng} / \mu \mathrm{L}), 5 \mu \mathrm{L}$ of total DNA $(200 \mathrm{ng} / \mu \mathrm{L}), 0.5 \mu \mathrm{L}$ of $2 \mathrm{U} / \mu \mathrm{L}$ Taq DNA polymerase (Amersham-Pharmacia Biotech. Inc., Piscataway, NJ, USA) and $62.5 \mu \mathrm{L}$ of autoclaved double distilled water. Amplification was in a model 2400 thermocycler (Applied Biosystems, Foster City, CA, USA) with a cycling profile of $94^{\circ} \mathrm{C}$ for $3 \mathrm{~min}$ followed by 25 cycles of $94^{\circ} \mathrm{C}$ for $1 \mathrm{~min}$, $50{ }^{\circ} \mathrm{C}$ for $1 \mathrm{~min}, 72{ }^{\circ} \mathrm{C}$ for $2 \mathrm{~min}$ and $72{ }^{\circ} \mathrm{C}$ for $10 \mathrm{~min}$. Amplification products were purified using ExoSap IT (Amersham-Pharmacia Biotech. Inc., Piscataway, NJ, USA) and submitted to a cycle-sequencing reaction using the fluorescent-labeled di-deoxy terminators supplied in the ABI Prism ${ }^{\mathrm{TM}}$ Dye Terminator Cycle Sequencing Ready Reaction kit (Applied Biosystems, Foster City, CA, USA). Sequencing reactions were performed in a Perkin Elmer 2400 thermocycler in a $10 \mu \mathrm{L}$ reaction mixture containing $2 \mu \mathrm{L}$ of DNA, $0.5(1 \mathrm{mM})$ of primer, $2 \mu \mathrm{L}$ of BigDye mix, $3 \mu \mathrm{L}$ of buffer ( $200 \mathrm{mM}$ Tris $/ 5 \mathrm{mM} \mathrm{MgCl} 2)$ and $2.5 \mu \mathrm{L}$ of autoclaved double distilled water, with a cycling profile of

Table 1 - Taxa from which sequences were obtained.

\begin{tabular}{lcll}
\hline Scientific name & Number of specimens & Common name & Collection locality or sequence origin \\
\hline Bradypus tridactylus & 1 & Three-toed sloth & Pará \\
Bradypus tridactylus & 1 & Three-toed sloth & GenBank AF069535 \\
Bradypus variegatus & 3 & Three-toed sloth & Pará \\
Bradypus torquatus & 2 & Maned sloth & Bahia \\
Mylodon darwinii & 1 & Giant Sloth & GenBank Z48944 \\
Choloepus didactylus & 3 & Two-toed sloth & Pará \\
Cyclopes didactylus & 2 & Silky anteater & Pará and Paraíba \\
Tamandua tetradactyla & 1 & Collared anteater & GenBank Z48946 \\
Tamandua tetradactyla & 2 & Collared anteater & Pará and Piaui \\
Myrmecophaga tridactyla & 3 & Giant anteater & Pará \\
Cabassous unicinctus & 1 & Armadillo & GenBank Z48940 \\
\hline
\end{tabular}

Bahia (BA), Pará (PA), Paraíba (PB), Piauí (PI) and São Paulo (SP) are Brazilian states. 
25 cycles of $96^{\circ} \mathrm{C}$ for $30 \mathrm{~s}, 50{ }^{\circ} \mathrm{C}$ for $15 \mathrm{~s}$ and $60{ }^{\circ} \mathrm{C}$ for $3 \mathrm{~min}$. Unincorporated di-deoxynucleotides were removed by isopropanol washing according to the method given in the ABI chemistry manual. The products were separated by electrophoresis $(3 \mathrm{~h}$ at $3.000 \mathrm{~V})$ and the sequences collected using the ABI Prism 377 automated sequencer. Also included in the phylogenetic analysis were previously published 16S GeneBank sequences from the sloth Bradypus tridactylus (Stanhope et al. 1998), the fossil giant sloth Mylodon darwinii (Höss et al., 1996), the anteater Tamandua tetradactyla and the armadillo Cabassous unicinctus (Table 1).

\section{Phylogenetic analyses}

The 16S gene sequenced in this work was aligned to homologous sequences obtained from the GenBank (Table 1) using the ClustalX program (Thompson et al., 1997) with default parameters and the data converted to FASTA and NEXUS formats. Minor modifications in the alignment were made using the BIOEDIT sequence editor (Hall, 1999). Nucleotide saturation was assessed by plotting transitions and transversions against K2P (Kimura, 1980) distances using the DAMBE program version 4.0.65 (Xia and Xie, 2001). The Modeltest program (Posada and Crandal, 1998) was used to select the model of evolutionary change that best fitted the data. Phylogenetic reconstruction was performed using the parsimony program PAUP version 4.0b10 (Swofford, 1998) and the Bayesian inference program MrBayes version 2.01 (Huelsenbeck and Ronquist, 2001). To estimate divergence times we adopted the strategy developed by Takezaki et al. (1995) in which sequences evolving excessively fast or slow were eliminated. The remaining sequences, selected thought the two-cluster test, were used to construct a linearized tree under the assumption of a molecular clock. The Shimodaira - Hasegawa test (Shimodaira and Hasewaga, 1999) and Wilcoxon's signed-rank test (Templeton, 1983) were used to compare trees at the $5 \%$ level.

\section{Results}

The mitochondrial rRNA 16 S gene was partially sequenced in 17 specimens from three Xenarthra families, the Bradypodidae (two-toed sloths), the Megalonychidae (three-toed sloths) and the Myrmecophagidae (anteaters). The two Cyclopes sequences (Para and Paraíba) were identical as well as the two Tamandua tetradactyla (Para and Piaui). The armadillo Cabassous unicinctus was used as an outgroup based on a sequence obtained from the Genbank (Table 1). The number of transitions and transversions were plotted as a function of p-distance and no saturation was observed. The G1 statistics for 10000 random trees was highly significant $(\mathrm{g} 1=0.666, \mathrm{p}<0.05)$, indicating a high level of genetic structuring in the sequence data (Hillis and Huelsenbeck, 1992). All shared gaps were considered as single events and treated as a fifth base for parsimony anal- ysis. The three Myrmecophaga tridactyla specimens shared a microsatellite region (AT) varying in size from 8 to $12 \mathrm{AT}$ repeats from sites 360 to 381 of the alignment, these repeats also being treated as a single event. Of the 521 aligned base pairs, 328 characters were constant and 193 were variable, there being 146 parsimony-informative characters. A branch and bound search recovered a single most parsimonious tree 350 steps in length (consistency index $(\mathrm{CI})=0.74$ and re-scaled consistence index $(\mathrm{RCI})=0.64)$. However, when gaps were treated as missing data the score of the most parsimonious tree dropped to 320 and the number of parsimony-informative characters to $140(\mathrm{CI}=0.72$ and $\mathrm{RCI}=0.62$ ).

For maximum-likelihood (MP), Bayesian (BI), Minimal Evolution (ME) and distance analysis, the parameters (equal base frequencies, transition-transversion ratio of 3.1585 , proportion of invariant sites $=$ zero and gamma distribution parameter with $\alpha=0.2804$ ) of the evolutionary model that best fitted the data were chosen using the Modeltest program version 3.06 (Posada and Crandal, 1998).

To be sure that markovian chains were converging to similar posterior probabilities, four PAUP generated random trees were used as user trees in four independent runs of the MrBayes program with the parameters selected by the Modeltest program. As all runs converged to similar posterior probabilities, we instructed the program to run one million generations (ngen $=10^{6}$ ), saving one tree to a file each 100 generations. The program run four simultaneous Metropolis-coupled Markov Chains Monte Carlo. The chains reached a stationary phase after about $2 \times 10^{4}$ generations, only trees sampled after this period being used to estimate posterior probabilities and branch lengths. A computer with a $1 \mathrm{GHz}$ Pentium III processor and 256 megabytes of memory was used to run 1000 bootstrap (BS) replicates for maximum parsimony (MP, run time $<1$ min) and maximum-likelihood (ML, run time $10 \mathrm{~h} 30 \mathrm{~min}$ ) which both produced the same $50 \%$ majority rule consensus tree (Figure 1). An alternative topology was produced by the minimum evolution (ME) method ( $1 \mathrm{~min} 30 \mathrm{~s}$ for $1000 \mathrm{BS}$ replications), the main difference in the topologies being the placement of Mylodon, which was closer to Bradypodidae in the MP/ML tree but grouped with Megalonychidae in the ME tree (not shown). Bremer decay index (BI) and Bayesian clade credibility (run time on the above cited computer for $10^{6}$ generations, 4 chains, about $2 \mathrm{~h} 10 \mathrm{~min}$ ) showed highly significant values (>96\%) for monophyly of the Bradypodidae. Conversely, parsimony $(82 \%)$, ML bootstrapping $(75 \%)$ as well as Bayesian posterior probabilities $(86 \%)$ were not able to shed light on the phylogenetic relationship of the Pleistocene fossil Mylodon darwinii to the extant two- and three-toed sloths. One topology (ME) connected Mylodon to the two-toed sloths but the other topologies (MP, ML, BI) produced trees, which placed Mylodon closer to the three-toed sloths. These alter- 


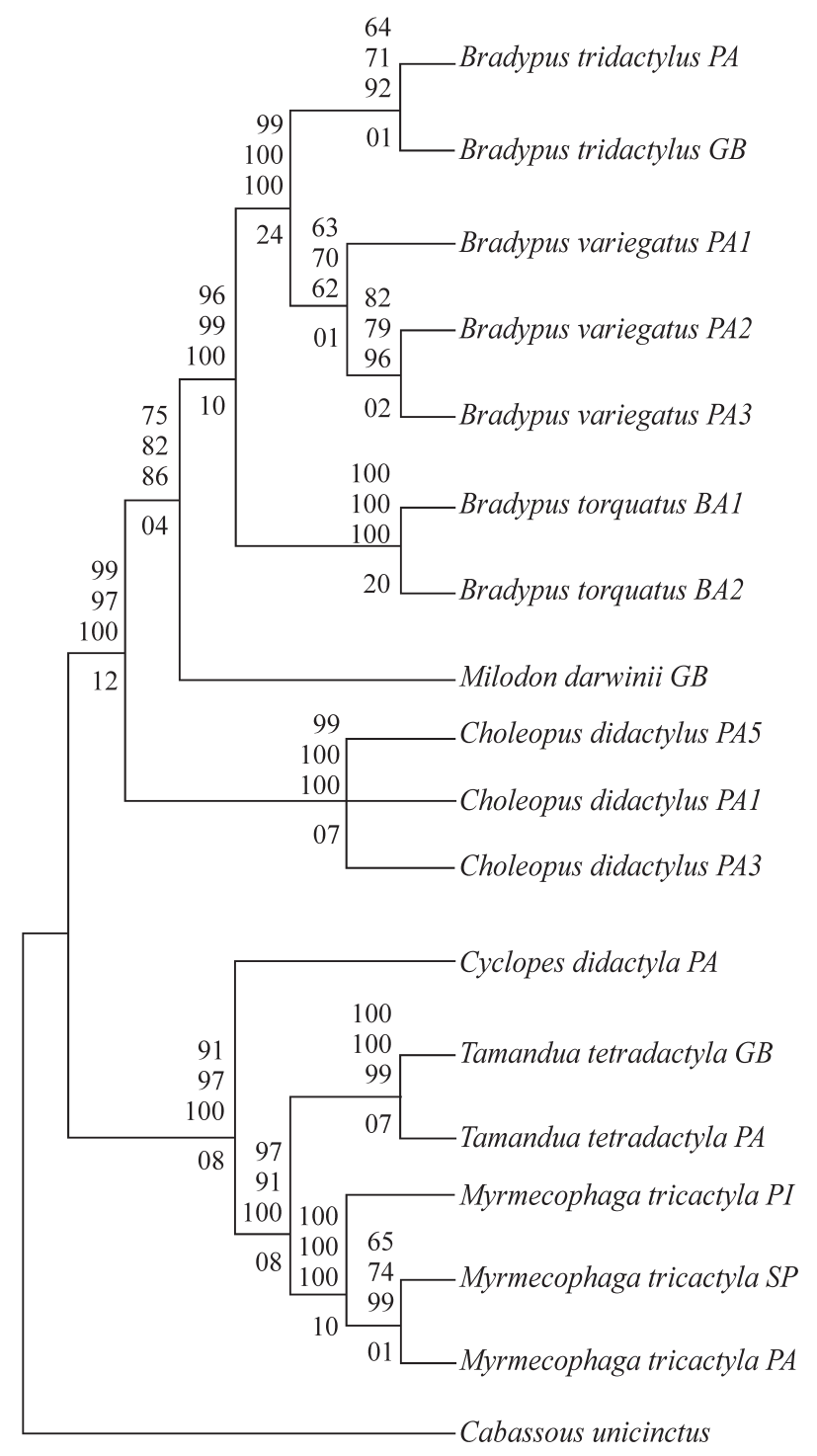

Figure 1 - Maximum likelihood phylogenetic tree obtained using a partial fragment of mitochondrial $16 \mathrm{~S}$ rRNA. The evolutionary model selected by Modeltest was the K2P model, equal nucleotide frequencies, transition-transversion ratio of 3.1585 and a gamma distribution of shape $\alpha=$ 0.3103 with zero of invariable sites modeling the site variation. Numbers above the branches indicates the maximum likelihood (1000 bootstrap replications), maximum parsimony bootstraps (1000 replications), and Bayesian posteriori probabilities, respectively. Numbers below branches show Bremer Decay indexes. For Bayesian inference (BI) we performed $10^{6}$ generations running four independent markovian chains with the evolutionary model chosen by Modeltest. Maximum-likelihood (ML), maximum parsimony (MP), minimum evolution (ME) and Bayesian analysis produced the same topology, with ME analysis showing Mylodon grouping with Choloepus.

native arrangements were compared using the Shimodaira Hasegawa test (Shimodaira and Hasewaga, 1999) and Wilcoxons signed-rank test (Templeton, 1983), both tests showed no significance at the $5 \%$ level (Table 2 ) which indicates that trichotomy best represents the relationship between the families Mylodontidae, Bradypodidae and Megalonychidae.
For the anteaters, in spite of the fact that MP and ML bootstrapping did not give strong support for monophyly of the Myrmecophagidae family (91\%), Bayesian posterior probabilities depicted a highly significant Bayesian posterior probability (BPP) value $(100 \%)$ for this clade. The topology shows Cyclopes as the basal lineage and Myrmecophaga and Tamandua sharing the most recent ancestor in this group.

\section{Molecular timings}

Once heterogeneous sequences were eliminated we constructed a linearized tree under the assumption of a constant rate of evolution. In practice we had to eliminate four sequences including Mylodon. Using 18MYA as the time of the split between the two and three-toad sloths as suggested by Delsuc et al. (2001) we calculated the ages for the remaining nodes without confidence intervals because in the paper of Delsuc et al. (2001) the calibration time was also estimated without standard error. In the Bradypodidae the split between Amazonian and Atlantic Bradypus was estimated as about 7.7 MYA, while in the Myrmecophagidae the first offshoot was Cyclopes at about 31.8 MYA followed by the split between Myrmecophaga and Tamandua at 12.9 MYA. We estimate the split between sloths and anteaters to have occurred about 37 MYA.

\section{Discussion}

\section{Sloths and anteaters}

The monophyly of each extant Megalonychidae, Bradypodidae and Myrmecophagidae family is very well supported by $16 \mathrm{~S}$ mitochondrial DNA data in all of our phylogenetic analyses, corroborating previous findings of nuclear DNA data alone or combined with mitochondrial DNA data (Delsuc et al., 2001). Monophyly also agrees with traditional morphological arrangements for this group (McKenna and Bell, 1997).

\section{Mylodon and extant sloths}

Our mitochondrial $16 \mathrm{~S}$ results show Bradypodidae as a monophyletic and robustly supported clade in all the analysis. However, the Pleistocene fossil Mylodon darwinii does not group significantly to either Bradypodidae or Megalonychidae (Choloepus) as showed by the Shimodaira and Hasegawa and Templeton tests (Table 2). Conversely, the cluster constituted by Mylodon, Choloepus and Bradypus is strongly supported, indicating that they indeed comprise a monophyletic group. These results are in disagreement with those of Greenwood et al. (2001) who concluded that the Mylodontidae (Mylodon darwinii) is associated with the Megalonychidae while the Megatheriidae (Nothrotheriops) is closer to the Bradypodidae. In fact, the mitochondrial Cytochrome B and $12 \mathrm{~S}$ data (alone or combined) analyzed by Greenwood et al. (2001) was not significantly supported by MP, Neighbor-Joining (Saitou 
Table 2 - The relationships of Mylodon darwinii as shown by alternative 16S phylogenetic topologies.

\begin{tabular}{|c|c|c|c|c|c|}
\hline \multirow[b]{2}{*}{ Trees } & \multicolumn{5}{|c|}{ Templeton test } \\
\hline & Length & Rank Sum & $\mathrm{N}$ & $\mathrm{z}$ & $\mathrm{P}$ \\
\hline Mylodon - Bradypus (BI, ML, MP) & 350 & Best & & & \\
\hline \multirow[t]{2}{*}{ Mylodon - Choloepus (ME) } & 355 & $48-18$ & 11 & -1.5076 & 0.1317 \\
\hline & \multicolumn{5}{|c|}{ Shimodaira-Hasegawa test } \\
\hline Trees & $-\ln \mathrm{L}$ & Difference in $-\ln \mathrm{L}$ & $\mathrm{P}$ & & \\
\hline Mylodon - Bradypus (ML) & 2253.21855 & Best & & & \\
\hline Mylodon - Choloepus (ME) & 2262.72420 & 9.50566 & 0.119 & & \\
\hline
\end{tabular}

$\mathrm{BI}=$ Bayesian inference, $\mathrm{ML}=$ maximum-likelihood, $\mathrm{MP}=$ maximum parsimony, $\mathrm{ME}=$ minimum evolution.

and Nei, 1987) or ML analysis. What these authors really showed was strong support (BS values of $100 \%$ ) for the monophyly of the group constituted by Choloepus (Megalonychidae), Bradypus (Bradypodidae), Mylodon (Mylodontidae) and Nothrotheriops (Megatheriidae), similar to the results obtained by us in the present work (although Nothrotheriops was not included in our analysis). Interestingly, Höss et al. (1996) using a concatenated dataset of $12 \mathrm{~S}$ and $16 \mathrm{~S}$ mitochondrial DNA obtained a phylogenetic tree that supports the hypotheses that Mylodon is more closely related to the two-toed sloths (Megalonychidae) than to the three-toed sloths (Bradypodidae) $(\mathrm{BS}=93 \%)$. Nevertheless, these results are somewhat conflicting because the Greenwood et al. (2001) $12 \mathrm{~S}$ data alone did not show significant support for the Mylodon x Choloepus grouping and our results with extended taxa sampling using 16S DNA alone also did not support a Mylodon x Choloepus clade. On the contrary our results produced a phylogenetic tree with Mylodon connected to Bradypus regardless of the non-significant bootstrap supports and posterior probability values $(\mathrm{ML}=75 \%$; $\mathrm{BS}=82 \% ; \mathrm{BPP}=86 \%$ ). This discrepancy probably can be explained by the reduced taxon sampling (five taxa) used in the work of Höss et al. (1996). Perhaps including the three very divergent Bradypus species as well as more Choloepus taxa will resolve this apparent incongruity. In fact, our current molecular database has more density of taxa than that analyzed by Höss et al. (1996) and higher support values were observed for the grouping of Mylodontidae with Bradypodidae. However, 16S DNA alone is not enough to solve this difficult question. Even with these minor disagreements all the analysis agree that the Mylodontidae (Mylodon), the Megalonychidae (Choloepus) and the Bradypodidae (Bradypus) represent a monophyletic group, which also probably contains the Megatheriidae.

\section{Anteaters}

Bayesian posterior probabilities (clade credibility values) and ML, ME and MP bootstrap analysis strongly support the monophyly of anteaters, showing Cyclopes as an early offshoot of the anteater radiation. They also fa- vored the assemblage of the semi-arboreal Tamandua with the strictly terrestrial Myrmecophaga as a recent sister group confirming findings based on nuclear exon 28 of the von Willebrand factor gene (vWF) (Delsuc et al., 2001) and myological (Reiss, 1997) and morphological (Gaudin and Branham, 1998) studies. However, Delsuc et al. (2001) found modest support for the monophyly of anteaters with 16S mitochondrial DNA data alone, probably under the influence of homoplasies affecting the phylogenetic signal of this moderately evolving molecule, as very ancient mammalian lineages were compared with the same database.

\section{Divergence time estimates}

According to Smith and Peterson (2002), age estimates from DNA sequences present some difficulties related to the variation of evolutionary rates both over time and among lineages. In spite of the many suggestions which have been made in attempts to overcome these problems there is no guarantee of an unambiguous separation of evolutionary rates and time. Nevertheless, age estimates derived from palaeontological and molecular data often agree reasonably well. Following Delsuc et al. (2001), we used 18 MY (representing the split between the two-toed and three-toed sloths) as the reference to estimate additional nodes of the Xenarthran tree. It is interesting to note that, based on morphological differences between two and three-toad sloths, Webb (1985) and Delsuc et al., (2001) argue that the apparent external similarities between two and three-toad sloths are a consequence of parallelism and that the arboreal life style may have evolved twice. In our view the argument that Bradypus and Choloepus have a diphyletic origin based on their morphological differences does not have enough support. A period of $18 \mathrm{MY}$ of radiation in the South America scenario seems to be enough to account for these differences. The three main families of New World primates began to radiate around the same period and extant members of this strictly arboreal monophyletic group have extreme morphological differences including a variety of distinct morphological adaptations for arboreal life, e.g. nails or claws and normal or prehensile tails (Schneider et al. 1993, 1996, 2001). Cur- 
rent evidence based on the scarce molecular data available clearly suggests that both extant sloths and the extinct Mylodon (and perhaps, as suggested by Greenwood et al. (2001), also Nothrotheriops) belong to the same monophyletic group and not to very distinct and divergent families as suggested by Webb (1985) and accepted by Höss et al. (1996), Greenwood et al. (2001) and Delsuc (2001). Considering that there is not enough significant support for the relationship between these four proposed families of sloths (Bradypodidae, Megalonychidae, Mylodontidae and Megatheriidae), a more conservative and cautious position to take until more evidence becomes available is to place each Pleistocene fossil (Mylodon and Nothrotheriops) and the extant sloths (Bradypus and Choloepus) in their own families (McKena and Bell, 1997).

According to our estimates, two Amazonian sloths of the Bradypodidae family (B. tridactylus and B. variegatus) diverged recently, only about 400 thousand years ago, although the split between the Amazonian and Atlantic forest Bradypodidae sloths (B. torquatus) occurred about 8 MYA. In previous work on New World monkey phylogeny we reached a similar estimate for the separation of two monkey genera (Brachyteles and Lagothrix) with similar geographic distribution (Brachyteles, like B. torquatus, being endemic to the Atlantic forest while Lagothrix, like $B$. tridactylus, occurs only in the Amazonian forest), based on nuclear genes we found that the split of Brachyteles and Lagothrix probably occurred around 10 MYA (Schneider et al. 1993, 1996; Goodman et al. 1998). Our interpretation is that $B$. torquatus evolved as a result of the same palaeogeographic barrier that kept Brachyteles isolated in the Brazilian Atlantic forest while Lagothrix as well as the proto $B$. variegatus/B. tridactylus evolved in the Amazon forest. In fact, evidence has accumulated which indicates that a major palaeobiogeographic event in the last 10 MYA is responsible for the differences in biodiversity seen today between the Amazonian and Atlantic rain forests (Lundberg et al. 1998). Based on nucleotide divergence and the split time of the Amazonian and Atlantic sloths, we suggest that the taxonomic status of these two groups should be revised to be coherent with the phylogenetic reconstruction, and that Amazonian and Atlantic bradypodid sloths deserve to be placed in separate genera as is the case for the monkeys Brachyteles and Lagothrix.

We estimate that for the anteater clade Cyclopes is the most ancient lineage, having separated from the remaining myrmecophagids at least 32 MYA, a slightly more recent date than that estimated by Delsuc et al. (2001). Our reconstruction based on molecular and morphological data strongly suggest that this ancient anteater lineage deserves the status of a different family, as proposed by Reig (1981). Furthermore, we dated the split between the two youngest anteater genera (Myrmecophaga and Tamandua) to about 12.9 MYA which corroborates the previous estimates of 13 MYA made by Delsuc et al. (2001).

\section{Final comments}

Understanding Xenarthran evolution is not an easy task. According to Patterson and Pascual (1972), the Xenarthra radiation occurred between the Paleocene and the Eocene when South America was already isolated from other continental masses. During this period tremendous palaeobiogeographic changes occurred in South American, such as the uplifting of the Andes which resulted in the establishment of a huge Amazonian lake about 12 MYA, and climatic changes due to glaciation about 12-10 MYA. The establishment of the Isthmus of Panama about 3 MYA allowed the exchange of fauna with the consequent invasion of South America by very specialist predators, the most recent process being the formation of the current Amazon Basin and the arrival of the most specialized predator, man, about 15 thousand years ago.

It seems that to elucidate the long and tough evolutionary pathway ambled by the sloths and anteaters in South America, the best strategy will be a combination of more conserved nuclear data able to reconstruct the most ancient evolutionary events and mitochondrial data powerful enough to detect recent splits, coupled to a extensive analysis of the comparative morphology of the large number of fossil forms available for this group.

\section{Acknowledgments}

We thank Marcia Chame of the Fundação Oswaldo Cruz for species identification, Dr. Niede Guidon for providing samples from the Parque Nacional da Serra da Capivara, Piaú, and Dr. João Morgante and Dr. Nádia de Moraes of the Universidade de São Paulo for providing samples of $B$. torquatus. This work was supported by grants from the Brazilian agencies Conselho Nacional de Desenvolvimento Científico e Tecnológico (CNPq), Coordenação de Apoio ao Pessoal de Ensino Superior (CAPES-PICD), Universidade Federal do Pará and Universidade Estadual do Maranhão.

\section{References}

De Jong WW (1998) Molecules remodel the mammalian tree. Trends of Ecology and Evolution 13:270-275.

Delsuc F, François MC, Stanhope MJ and Douzery EJP (2001) The evolution of armadillos, anteaters and sloths depicted by nuclear and mitochondrial phylogenies: implications for the status of the enigmatic fossil Eurotamandua. Proceedings of the. Royal Society of London 268:1605-1615.

Engelmann GF (1985) The phylogeny of the Xenarthra. In: Montgomery GG (ed) The evolution and ecology of armadillos, sloths and Vermilinguas, Smithsonian Institution, Washington, DC, pp 51-63.

Gaudin TJ (1999) The morphology of xenarthrous vertebrae (Mammalia: Xenarthra). Fieldiana Geol 41:1-38.

Gaudin TJ and Branham DG (1998) The phylogeny of the Myrmecophagidae (Mammalia, Xenarthra, Vermilingua) 
and the relationship of Eurotamandua to the Vermilingua. Journal of Mammalian Evolution 5:237-265.

Greenwood AD, Castresana J, Feldmaier-Fuchs G and Paabo S (2001) A molecular phylogeny of two extinct sloths. Molecular Phylogenetics and Evolution 18:94-103.

Goodman M, Porter C, Czesluniak J, Page Sl, Schneider H, Shoshani J, Gunnel G and Groves C (1998) Toward a phylogenetic classification of primates based on DNA evidence complemented by fossil evidence. Molecular Phylogenetics and Evolution 9:585-598.

Hall TA (1999) BioEdit: a user-friendly biological sequence alignment editor and analysis program for Windows 95/98/NT. Nucleic Acids Symposium Series 41:95-98.

Hillis DM and JP Huelsenbeck (1992) Signal, noise, and reliability in molecular phylogenetic analyses. Journal of Heredity 83:189-195.

Höss M, Dilling A, Currant A and Paabo S (1996) Molecular phylogeny of the extinct ground sloth Mylodon darwinni Proceedings of the National Academy of Sciences USA 93:181-185.

Huelsenbeck JP and Ronquist F (2001) MrBayes: Bayesian inference of phylogenetic trees. Bioinformatics Application Note 17:754-755.

Kimura M (1980) A simple method for estimating evolutionary rate of base substitutions through comparative studies of nucleotide sequences. Journal of Molecular Evolution 16:111-120.

Lundberg JG, Marshal LG, Guerrero J, Horton B, Malabarba MCSL and Wesselingh F (1998) The stage for neotropical fish diversification: a history of tropical South American rivers. In: Malabarba RR, Reis, RR, Vari RP Lucena ZMS and Lucena CAS (eds) Phylogeny and Classification of Neotropical Fishes. Part 1 - Fossils and Geological evidence. Editora da PUC Rio Grande do Sul, Porto Alegre.

McKenna MC and Bell SK (1997) Classification of Mammals above the Species Level. Columbia Univ. Press, New York.

Murphy WJ, Eizirik E, Jonhson WE, Zhang YP, Ryder OA and O'Brien SJ (2001) Molecular phylogenetics and the origins of placental mammals. Nature 409:614-618.

Takezaki N, Rzhetsky A and Nei M (1995) Phylogenetic test of the molecular clock and linearized trees. Molecular Biology and Evolution 12:823-833.

Palumbi SR, Martin A, Romano S, Mcmillan WO, Stice L and Grabowski G (1991) The Simple Fool's Guide to PCR. University of Hawaii Press Honolulu.

Patterson B and Pascual R (1972) The fossil mammal fauna of South America. In: Keast A, Erk FC and Glass BP (eds) Evolution, mammals and southern continents, State University of New York Press, Albany, NY, pp 247-309.

Patterson B, Segall W, Turnbull WD and Gaudin TJ (1992) The ear region in xenarthrans (Edentata, Mammalia). Part II. Sloths, anteaters, palaeanodonts, and a miscellany. Fieldiana Geology New Series 24:1-79.

Posada D and Crandal KA (1998) Modeltest: testing the model of DNA substitution. Bioinformatics Applications Note 14:817-818.

Reig OA (1981) Teoria del origem y desarrollo de fauna de mamiferos de America del Sur. Monographie Naturae. Mar del Plata, Argentina. Museo Nacional de Ciencias Naturales Lorenzo Sacaglia.
Reiss KZ (1997) Miology of the feeding apparatus of myrmecophagid anteaters (Xenarthra: Myrmecophagidae). Journal of Mammalian Evolution 4:87-117.

Rose KD and Emry RJ (1993) Relationships of Xenarthra, Pholidota and fossil Edentates the morphological evidence. In: Slazay FS, Novacek MJ and McKenna MC (eds) Mammal Phylogeny Springer-Verlag, New York.

Saitou N and Nei M (1987) The neighbor-joining method: a new method for reconstructing phylogenetic trees. Molecular Biology and Evolution 4:406-425.

Sambrook J, Fritsch EF and Maniatis T (1989) Molecular cloning: a laboratory manual. 2nd ed. Cold Spring Harbor Laboratory Press, Cold Spring Harbor.

Schneider H, Sampaio I, Tagliaro CH, Canavez F and Seuanez H (2001) Can molecular data place every Neotropical monkey in its own branch? Chromosoma 109:515-523.

Schneider H, Schneider MPC, Sampaio I, Harada ML, Stanhope M and Goodman M (1993) Molecular phylogeny of the New World monkeys (Platyrrhini, Primates). Molecular Phylogenetic and Evolution 2:225-242.

Schneider H, Sampaio I, Harada ML, Barroso CML, Schneider MPC, Czelusniak J and Goodman M (1996) Molecular phylogeny of the New World monkeys (Platyrrhini, Primates) based on two unlinked nuclear genes: IRBP intron 1 and å-globin sequences. American Journal of Physical Anthropology 100:153-179.

Shimodaira H and Hasegawa M (1999) Multiple comparisons of log-likelihoods with applications to phylogenetic inference. Molecular Biology and Evolution 16:1114-1116.

Smith AB and Peterson KJ (2002) Dating the time of origin of major clades: molecular clocks and the fossil record. Annual Reviews Earth and Planetary Sciences 30:65-88.

Stanhope MI, Madsen O, Waddell VG, Cleven, GC, De Jong W and Springer MS (1998) Highly congruent molecular support for a diverse superordinal clade of endemic African mammals Molecular Phylogenetics and Evolution 9:501508.

Swofford, DL (1998) PAUP* Phylogenetic Analysis Using Parsimony (*and other Methods) Version 4 Sinauer Associates, Sunderland, Massachusetts.

Templeton AR (1983) Phylogenetic inference from restriction endonuclease cleavage site maps with particular reference to the evolution of humans and the apes. Evolution 37:221244.

Thompson JD, Gibson TJ, Plewniak F, Jeanmougin F and Higgins DG (1997) The ClustalX windows interface: flexible strategies for multiple sequence alignment aided by quality analysis tools. Nucleic Acids Research 24:4876-4882.

van Dijk MAM, Paradis E, Catzeflis F and Jong WW (1999) The virtues of gaps: Xenarthran (Edentate) Monophyly supported by a unique deletion in $\int \mathrm{A}-\mathrm{Crystallin}$. Systematic Biology 48:94-106.

Webb SD (1985) The interrelationships of tree sloths and ground sloths. In: Montgomery, GG (ed) The Evolution and Ecology of Armadillos, Sloths, and Vermilinguas, Smithsonian Institution, Washington, DC, pp 105-112.

Xia X and Xie Z (2001) DAMBE: Data analysis in molecular Biology and evolution Journal of Heredity 92:371-373.

Associate Editor: João S. Morgantes 